\title{
CO-OPERATION BETWEEN PHYSICIAN AND PSYCHIATRIST IN PSYCHO-SOMATIC MEDICINE
}

\author{
By Maurice Davidson, M.A., D.M., F.R.C.P. \\ Consulting Physician to the Brompton Hospital, the Miller General Hospital and the Western Ophthalmic Hospital \\ President of the Section of Medicine, Royal Society of Medicine
}

\author{
G. W. B. James, C.B.E., M.C., M.D., D.P.M. \\ Physician in charge of the Psychiatric Department, St. Mary's Hospital \\ and \\ J. S. Richardson, M.V.O., M.A., M.D., F.R.C.P. \\ Physician to Out-Patients, St. Thomas's Hospital
}

The following are the opening papers delivered at a meeting of the Section of Medicine of the Royal Society of Medicine on May 25th, 1948. They are here reproduced by the courtesy of the Honorary Editors of the Royal Society of Medicine, since they appeared to form an appropriate introduction to this special number of the "Post Graduate Medical Fournal.'

Dr. Maurice Davidson :-Ladies and Gentlemen, I should like to make a few brief observations by way of introduction to our discussion this evening. I do not propose to enter to any great extent into the many specific details which this important subject is bound to raise ; my object is rather an endeavour to discharge what, as I said to you in my Presidential Address two years ago, I have conceived to be the primary function of my office, that is to say the exercise of a certain leadership, the guidance of the section into appropriate channels, and in so doing to preserve that attitude of impartiality and judicial sense which is so necessary to a clear understanding of the real issues that lie before us.

The expression 'team work' as applied to medicine has become very popular in recent years. I cannot help feeling that many of those who use it most frequently are wont to do so because they think it the proper thing to say, and that their professed obligation to carry out the principle which it embodies is honoured in the breach rather than in the observance. Real team work implies some sacrifice of immediate personal interests, and this in an age of materialism and opportunism is not always easy. It is, nevertheless, of paramount importance that we should realize this ideal if the efficiency and the ethical standards of British Medicine in the future are to maintain the reputation which they have justly. held in the past.

Co-operation between colleagues is essential to full understanding of the complex and difficult problems that arise in any branch of medicine, and not least in that with which we are concerned this evening.

The crystallization of ideas which began with the pioneer work of Freud and his disciples and which led up to the formal recognition of psychiatry as a specific branch of medical science is a comparatively recent phenomenon, but the fundamental needs with which this speciality deals have been recognized for centuries by all whose deepest interests have lain in the study of human personality. In a recent work on practical clinical psychiatry ${ }^{1}$ I came across the following passage :-

'The basic idea of psycho-somatic medicine is very ancient. More than 2,500 years ago the wise Socrates, returning from the Thracian campaign, reported that the Thracians realized that the body could not be cured without the mind. "This," he said, "is the reason why the cure of many diseases is unknown to the physicians of Hellas, because they are ignorant of the whole.",

That which the wise Socrates noted of the physicians of his time is equally true today, and I would commend his trenchant observation to the notice of this meeting, and especially to the Section of Medicine. We have much to learn from our colleagues in the Section of Psychiatry. What I am anxious to elucidate this evening (and I hope that those who take part in the discussion will bear this in mind and will accept this suggestion as a lead to the general trend of our debate) is a clearer idea of the proper scope and the necessary limitations of physician and psychiatrist alike in dealing with various disorders of health in which their functions must inevitably to some extent overlap. I feel sure that in saying this I shall not be misunderstood by our friends in the Section of Psychiatry or lay myself open to the 
disgraceful charge of dabbling in a special science in which I have no proper training or apprenticeship. What I am pleading for, and it is mainly to physicians in consulting practice that I say this, is the cultivation in greater measure of that sanity of outlook, so necessary for successful practice of their art, that will compel them to view the patient as a whole rather than in watertight compartments.

When I look back upon my student days, over 40 years ago, I am conscious of what then appeared and what still appears to me to be the grotesque inability of the average consultant in medicine to grasp the importance of this comprehensive view of disease and to realize that in organic as well as in functional disorders mind and body react on each other, often to the extent of producing a vicious circle which may be extremely difficult to break. Many patients in those days who sought medical advice did so on account of various subjective symptoms for which no corresponding structural organic changes could be demonstrated. They were often rather abruptly dismissed as ' functional,' the very tone of voice in which this expression was used betraying the mingled pity and contempt with which they were regarded by the examiner, who, by the way, was not necessarily always a junior practitioner. Yet they were none the less sick persons, and they would often go the round of hospital after hospital seeking relief.

This extreme example of professional obtuseness is, perhaps, less prominent today since psychology has come more into its own, but there is still a lamentable neglect on the part of many physicians and surgeons of the psychological aspects of the picture in cases of organic disease. It is true that demands have been put forward for the inclusion of psychological medicine in the already overloaded medical curriculum, but even this would hardly solve the real problem, as I see it, which is primarily a question of greater individual efforts at real cooperation between teaching physicians and psychiatrists. Much excellent advice on these lines is to be found in medical literature, but the instinctive carrying out of such precepts in routine medical practice is confined to the comparatively few in our profession. When one does encounter it it seems to spring rather from a rare faculty in the individual practitioner than as a result of traditional training and medical education.

As I have already said, it is unnecessary for me to dwell in detail upon the many organic diseases in which the element of stress and strain and of anxiety bulks so largely, but I believe that this element, apart from its obvious relation to successful treatment, is often also of considerable importance as an aetiological factor. In the minds of really educated physicians and in the experience of the best types of general practitioner this must surely be axiomatic. The mental worry which so frequently accompanies such conditions as cardiovascular hypertension, duodenal ulcer, or progressive polyarthritis may be mentioned as an example of the psycho-somatic problem and of the vicious circle to which $I$ have already referred, in which mind and body react upon each other until it almost becomes a difficulty to know just where to begin in the effort to break it. The effect of severe emotional shock or of prolonged mental strain in precipitating the clinical manifestation of a dormant tuberculous lesion in the lung is well known to all phthisiologists of experience. The same may be said of the inhibiting influence of the strict sanatorium regime upon the phthisical patient and of the extent to which such a regime, necessary and inevitable though it is in the earlier stage of treatment, may sometimes militate against the subsequent rebuilding of the patient's selfconfidence and initiative, without which it is impossible to restore him to working efficiency and to a really healthy state of body and mind.

I have said enough, I think, to indicate the broad principles which were in my mind when I thought of the subject of this evening's debate and the general direction in which I suggest that our discussion should proceed. There is one point in particular to which in conclusion I would again make reference; this is the proper scope and the limitations of the physician and the psychiatrist, for I think this is a question which requires some adumbration. It has been said, and not without reason, that every physician should be his own psychologist, and I think you will agree with me that there is a sense in which this is undoubtedly true. In days gone by the old family physician, who made no claim to be a scientist, was a sort of combination of medical advisor and father confessor. His knowledge was mainly empirical, but he did possess a very shrewd insight into human nature, and he recognized as part of his vocation the need to bring this insight to bear upon the problems for which his patients sought his advice and looked to him for definite guidance on which they could, and in fact did, rely. I cannot help thinking that in many ways he gave them better service than some of our modern specialists, who have been so trained in the cold sciences of physiology and bio-chemistry that they have lost the practical art of handling and managing the affairs of sick people. The physician who realizes this truth (and there are still a few of them left), requires some guidance as to just what the psychiatrist can do and what he cannot, and does not profess to do, for all of us have our limitations and none of us can make two plus two into five. 
I feel strongly that there are many borderline cases in which the lack of real practical cooperation between colleagues who represent our respective sections results in needless misunderstanding, to the worry of the patient and his relatives, and to the detriment of his mental and bodily health. This is the question that I am most anxious to elucidate, and it is in the earnest desire for greater rapprochement between the Section of Medicine and the Section of Psychiatry that I have arranged this meeting, in the hope that by frank and even perhaps provocative discussion we may draw nearer together in a common aim for the greater service of those unhappy individuals to whose needs it is our mutual function to minister.

\section{REFERENGE}

I. STRECKER, E. A., EBAUGH, F. G., EWALT, J. R. (1947). 'Practical Clinical Psychiatry,' 6th Edition, 4r 3, Philad., The Blakiston Company.

Dr. James :-Mr. President, Ladies and Gentlemen, it is, indeed an honour to be invited to take part in this discussion as a psychiatrist among physicians. Your own wise remarks have placed the discussion on a high level which I must strive to maintain. A discussion like the present is an indication of the greatly increased interest which is being shown by physicians in the subject known as psychiatry, an interest which can surely only benefit us in psychiatry, even if we have our subject given new and, no doubt, more respectable names. Psycho-somatic Medicine, Social Medicine, Industrial Medicine surely indicate limited and special aspects of psychiatry, an art, as you Sir have reminded us, which concerns the study of the human personality, the problems of human thought, feeling, and conduct in health and disease. Psycho-somatic manifestations in man provide the ground on which we are perhaps closest in our work. But this interest in psychiatry on the part of physicians is comparatively recent and has perhaps been stimulated by experience gained in two world wars, in which psychosomatic manifestations have been one of our more serious problems in the medical services of fighting men.

In the recent world war it was my privilege to meet physicians from all parts of the British Enpire as well as from the countries of our allies, and $I$ felt bound to record in an address to the Section of Psychiatry (1945) that the doctors of the Empire, no matter whence they came or where they were trained, were, with few exceptions, bewildered by the psychiatric casualty; they usually looked upon him with distaste, and were quite unable to deal with him effectively. Immediate and simple therapy in the field tended to be replaced by an earnest searching for tropical disease, allergies or septic foci, often with the aid of many negative $\mathrm{X}$-ray examinations. As a last resort the neurotic patient was given a strange label, of which I quote two examples :- Bomb blast to conjunctivae'; and 'Battle exhaustion left leg' ; the one to cover an hysterical blindness and the other an hysterical monoplegia. With such strange labels (and many like them) the physician was content to leave the patient to his own devices, usually, alas ! in a hospital bed.

This dislike or resentment of patients whose condition may be said to be emotional or ecological rather than physical in origin is, in my experience, shared by students of medicine who shuffle and drift away when emotional factors in a given case are discussed. That at least is my experience, and every year I blame myself for not knowing quite how to allay such resentment of the psychiatric patient, for this is the root of any division that there may be between physician and psychiatrist. We psychiatrists are said to indulge in a difficult vocabulary and to obscure our meanings in verbiage. This is no doubt sometimes true, but it must, perhaps, be tolerated in a young and growing medical speciality. A physician objecting to psychiatry on the gound of nomenclature should take the opportunity of listening to a meeting of our colleagues - who deal in the same developmental layer of the body -in the speciality of dermatology. Neither the student of medicine not his teachers are enthusiasts for psychosomatic medicine, and, as you have said, $\mathrm{Mr}$. President, this is as true today as when Socrates in his campaigns deplored the ignorance of the psychic aspects of disease by his colleagues. Perhaps there will be time to touch on the reasons for this later. Now I must turn to try and set out what the psychiatrist can do to help the physician in dealing with psycho-somatic disorders, and must attempt to suggest where the physician requires special help. First I would put the psychiatrist's ability to demonstrate to the physician the high importance of assessing the intelligence levels of psycho-somatic cases. I feel strongly.that this is often overlooked by our colleagues in medicine. It is important for three main reasons. First, the somatic disease itself may be a reflection of low intelligence and an inability to safeguard health by the normal restraints and precautions of civilized living - such conditions in my experience include many cases of venereal disease, skin disorders such as scabies and artefacts and infestations such as pediculi. Secondly, low levels of intelligence are found often in people who express by somatic symptoms their emotional unhappiness, their dissatisfaction with their environment, or perhaps their inability to perform the work to which they have been put, often resulting from a promotion. As a result of this somatic presentation they may 
be sent to a physician for advice. Lastly, it is asking too much of the psychiatrist to send to him a patient who is so far below average intelligence as to make any form of successful psychotherapeutic treatment an impossibility, since the unfortunate psychiatrist may then have to accept the unjustifiable blame of failure.

It is not my intention to labour this point but it is highly important to know something of the intelligence levels of our patients in the appraisal of all medical cases. Our out-patient departments are much used by persons of subnormal intelligence with all sorts of somatic complaints who are helped through life by the dicta of their physician, his bottle of medicine, and his cheery or bad tempered encouragement-it does not seem to matter very greatly which !-and neither physician nor patient is aware of the true state of affairs. W. Trotter in his Lloyd Roberts lecture to this Society in 1935, called attention to this common tendency to accept the intellect ' as an apparatus already perfected, needing no exercise or instruction, but sprung into being ready to carry out its functions without flaw or friction. In actual fact it is as much a biological product as the bodily organs, and subject to similar conditioned functioning; it is as squeamish in its way as the stomach, and as selective as the kidney or choroid plexus.' We psychiatrists feel that this matter of intelligence, especially the subnormal intelligence so often linked to emotional instability, is still not adequately appreciated by our colleagues in medicine.

Then there is the psychiatric history. I have found physicians surprised and interested to learn that in many, in fact nearly all, psychosomatic patients there are certain constant features in the history. The illness or one like it, has often occurred before, in which case it gives an opportunity to investigate the emotional background of its first appearance. Psycho-somatic illness has occurred in other members of the family, occupations have.been changed significantly and patients frequently recount evidences of neurotic disorders in childhood. The family story also tends to follow a pattern; quarrelling or separated parents, divorces, untimely illness or death of a parent or parents, an orphan childhood or illegitimacy. Again I do not want to dwell on these points but the psychiatric history is quite as important as the question of intelligence and is not always elicited by the physician, who is perhaps too shy or too kind to ask such searching questions.

The next matter which in my view the psychiatrist can materially assist his colleague the physician is in the treatment of the psychosomatic patient, yes, even if his intelligence is low. After all, this is why most psycho-somatic cases are referred to the psychiatrist, viz. to get help in a problem which the physician finds is to some extent outside his province. It may be well just to keep an eye on figures in hospital practice. In my department at St. Mary's Hospital, Mrs. D. N. Hardcastle, psychiatric social worker to the department has analysed the last 449 cases referred to us and finds, in round figures, that 20 per cent. of them may fairly be termed psychosomatic. Of these, half are found suitable for special treatment, and just over half the cases receiving special treatment make a recovery, that is, become free from psychic and somatic symptoms, are able to return to normal work, and are contented in family. relations. Many others are improved. So that over 25 per cent. of psychosomatic cases referred do benefit materially by special methods of psychiatric treatment, of which psychotherapy is by far the most usual. The cases referred include asthma, dyspareunia gastrointestinal disorders such as anorexia and colitis, impotence, polysymptomatic hysterics, and a few depressions, which latter frequently come for advice primarily for somatic disorders. This is not a very impressive recovery rate but it approaches the one-third average recovery rate which seems to be remarkably constant in psychiatry and which compares not unfavourably with out-patiene results in other medical departments. This psychiatric treatment has certain attributes which I think a psychiatrist is entitled to emphasize at this meeting. You, Sir, in your admirable introduction spoke of team work in treatment. The psychiatrist does truly use an extensive team, not all of it medically qualified. His psychologist will tell him of the patient's intellectual level and will give very valuable hints from personality studies in those difficult cases in which one seeks to differentiate psychotic from neurotic or an affective from a schizophrenic psychosis. The psychiatric social worker with her clerks form an invaluable link with the patient and his or her home and work, his or her marital situation, or the family problems and burdens which are lying so heavily on so many in these days. And by means of the psychiatric social worker the psychiatrist makes contact with public authorities, and with all sorts of helpful societies.

As regards his medical work the psychiatrist must surround himself with expert helpers-and I speak now only of out-patients-the psychotherapists, the experts in electro-convulsive therapy and electro-narcosis, the highly expert and specialized sisters and nurses, the technicians who translate the electro-encephalograms, the social club which is such a valuable method of helping people to return to health, all these add up to a formidable team. In a psycho-somatic case the 
emotional life and environment of the patient are every whit as important as the body. Indeed, if these aspects of the psycho-somatic case are to be neglected by the doctor, we might just as well recommend our students to take their qualifications at the Royal Veterinary College.

I would like to return to the subject of the dislike or resentment of the psychiatric case among doctors ; it is a real phenomenon of which I saw much during the late war. Of course the scientific research worker does not care for matters which he cannot estimate or weigh with precision. It must be admitted that one cannot reduce emotion, environment, or conduct to milligrams per cent. Here is an important source of dislike-the physician does not care to deal in intangibles. He is further puzzled by and inclined to shun the extraordinary methods of treatment used by the psychiatrist-apart from psychotherapy there are continuous narcosis or "poisoning with the barbiturates,' in dosages which seem to the physician a nightmare, the coma produced daily by the hypoglycaemia following an early morning ' overdose of insulin,' electric convulsive therapy, or the administration at will of severe epileptic seizures by the passage of an electric current through the brain, electro-narcosis induced by the passage of a measured milliamperage through the brain, the division of the frontal lobes in prefrontal leucotomy. Even the psychiatrist's methods of investigation must seem strange to a scientific physician - the study of personality by a series of ink blots, the electro-encephalogram from which confident deductions are made, the coloured blocks and lists of oral questions. What is the rationale of such methods and such treatments? They are empirical and as such are almost abhorrent to the physician. I had hoped that the physical methods of treatment with their very remarkable results would have roused widespread interest among physicians, who ought to know much of their applicability in psycho-somatic cases. There is a wide field for research here, and it is not going to be possible for the psychiatrist to undertake it all. The physical methods of treatment are in process of revolutionizing the mental hospital ; the outlook for mental nurses has been completely changed within ten yearsmen and women are offered a stimulating career with the opportunity of applying highly skilled techniques which earn them good pay and the better reward of watching recoveries similar to those of the surgeon's nurses. The fact that these methods are empirical and have sprung from theories which have the slenderest scientific basis in no way reduces their value in practice. As Sargant and Slater have said (I944), 'It is into the hands of the bold experimenters that success has fallen.' And the psychiatrist badly needs the help of his scientific medical colleagues in the closer investigation of these methods which are producing such promising results in the relief of human suffering and the appalling social burden of chronicity.

There is yet another source from which I believe the aversion among physicians to psychiatry and the psychiatric patient springs. In all our psychiatric work of the last 50 years it has become increasingly clear that the pioneer work of Freud has resulted in a widely spread acceptance among psychiatrists of the very primitive origins of mind. I can well remember my own revulsion when introduced to embryology as a medical student. How could it be possible that this majestic creature; homo sapiens, could begin life as a sort of evoluting amphioxial tube developing knobs rather like a twisted pawnbroker's sign? It was only when I learned more and appreciated the wide practical applications of embryology, and learned to see the history of the race repeated in every developing individual that instinctive revulsion was overcome and intellectual interest took its place. I feel physicians are in a similar situation with regard to the embryology of the mind. People do not like to think that the mind develops from primitive infantile mental processes. It can only develop that way. Inescapably we are biological creatures evolving slowly from humble beginnings. The mind is no exception-the springs of conduct and emotion, rage, fear, hate, love, have simple origins indeed and we psychiatrists are perhaps only beginning to realize and apply the social implications of Freud's discoveries. The psychiatric patient arriving in a mental hospital is not an acutely sick person in the sense that a patient with pneumonia is acutely ill, but is suffering from a condition - which may well have its origins in infancy and have incubated over many years. The beginnings of mind revolve around the feeding activities of the infant, and his later training in the control of his excreta. It has always seemed to me that the psycho-somatic difficulties in children should perhaps make us aware of the primitive nature of the young mind. Enuresis, fads and resistances in diet, and the obstinate constipations of young children are good examples. The bladder, the mouth, the anus; provide an early and dynamic trinity of interests. Adults still lead miserable lives because their totally ignorant or superstitious parents, sometimes even when thcy are also doctors, avoid treatment for the child by saying, "I do not believe in psychology.' It is a common attitude and is very similar to the expression "I do not believe in inoculation or vaccination.' Quite defenceless children untoxoided and unvaccinated still die of 
diphtheria or smallpox, while the child with early anxieties or conflicts slowly develops into the neurotic or psychotic adult. If there is one thing I hope for with all my heart, it is that physicians shall one day think of psychiatry as part of their essential training. We psychiatrists agree that we should be experienced in general medicine-it is the foundation of all medical specialities. We have even submitted to a post graduate training which includes a stiff examination in the somewhat barren discipline of neurology. I would like to see that time spent by candidates for the D.P.M. in acquiring a much greater knowledge of children, and a solid training in anthropology.

But may I make a plea for physicians to acquire some experience of psychiatry as part of their own medical training ? The best way to know something of the minds of patients is to acquire knowledge of one's own. mind and the way it works. When I am asked by physicians what they should do to acquire such knowledge, my answer is to advise a training analysis. In this way physicians would gain not only insight into and an ability to treat psycho-somatic and other psychiatric cases, but might find also that the answer to the aetiology of certain bodily ills begins like some mental illness, in the primitive developing mind of the infant ? For example, perhaps the first step to a duodenal ulcer may be disorder in the mind of an infant, incubating until the character of the ulcer-prone individual is fully formed, when in the fullness of time the somatic element would add itself to the psychic. This audience, Sir, will be saying to itself-' What typical woolly psychiatric stuff' and so I will speculate no more. I may have said enough to start a discussion, which is my function. May I end by suggesting to you that united we physicians and psychiatrists are probably the best hope of a sick world. Man is carrying a tremendous load of emotional disability. With his wonderful aptitudes and every growing scientific knowledge he is, as yet, lamentably unable to manage his fears, his guilt, his hates and his aggressions. He lives by outworn standards imposed on him by grandparents. Is it surprising that he often finds some relief in psycho-somatic illness? We doctors have a great responsibility in present times. It is our duty to learn all we can of the primitive mind, and of our own minds. The physician, as Macfie Campbell used to say, is still too ready to regard his patient as 'the more or less incidental container of an interesting bio-chemical, physiological, bacteriological and pharmacological situation.'

That is too simple for the times. The psychiatrist (and soon, I hope, the physician), to paraphrase Peabody, does not think of a clinical picture as a photograph of a man sick in bed, but rather as an oil painting of the Flemish School with a patient surrounded by his home, his work, his relations, his friends, his joys, sorrows; hopes and fears. And the psychiatrist, like the old master, wants to know all about the earthy substances which make the pigments of the paint by which that picture is built.

\section{BIBLIOGRAPHY}

JAMES, G. W. B. (1945), 'Psychiatric Lessons from Active Service,' Presidential Address to Section of Psychiatry, Royal Society of Medicine, Lancet, 2, 80 r.

SARGANT, W., and ELIOT SLATER (1944), 'An Introduction to Physical 'Methods of Treatment in Psychiatry,' E. \& S. Livingstone, Edinburgh.

TROTTER, W. (1935), Lloyd Roberts Lecture, Royal Socie ty of Medicine, B.M.尹., 2, 609 .

Dr. Richardson :-Mr. President, Ladies and Gentlemen, I wish to follow the example of Dr. James in accepting the suggestion that you, Sir, gave in your opening address as to the direction of this discussion, and to take this opportunity for giving my views on the principles that should govern the scope and limitations of the general physician and the psychiatrist in dealing with problems that concern them both. I desire to make it clear at the outset that I am thinking solely of so-called psycho-somatic medicine, and I am not considering the question of the psycho-s neuroses as, although the division is an artificial one, they are essentially the province of the psychiatrist.

The term psycho-somatic medicine I take to have one of two meanings. It can be regarded as denoting either a guiding principle, a point of view, a way of thought, or as referring to a limited number of conditions where the results of emotional disturbance dominate the clinical picture as somatic expressions. The intimate connection of the body and mind in health and thus in disease is a self evident proposition to most educated people, whether medically qualified or laymen, and has been for a great number of years, although it is clear from the writings of many psychiatrists that they would except physicians from sharing this perception. Our President has quoted Socrates as appreciating this, and I would like to suggest another who lived some 2,500 years ago as an example, namely Buddha, the Enlightened One. Gautama was inspired I feel by the truth that the body and mind are intèrwoven as he sat under the Bo Tree and evolved his immensely complex discipline for loosening and separating them.

The first meaning that I have attributed to the term psycho-somatic medicine needs, therefore, no explanation, in principle, but requires perpetual consideration in practice and enters into the management of every case of prolonged illness 
from a fractured femur to an advanced case of pulmonary tuberculosis, as well as into many problems of clinical research. It is when we consider the second and more popular meaning that we may come up against difficulties. The realization that certain well recognized and frequently encountered diseases that have been accepted as organic since they were first described, have in fact a largely psychological basis, is comparatively new. It is natural therefore that physicians should examine critically this new conception and not surprising, though regrettable, that a fecling of resentment, so easily aroused by any infringement of previously possessed territory, should sharpen this criticism and reduce its impartiality. This stage of resentment was prolonged, no doubt due to the obstrurtive and even scornful attitude of physicians but it is only fair to say that they were encouraged in this by the grandiose claims for their subject and omniscent approach adopted by some psychiatrists. Again the rapidly changing and often unlovely jargon of this newly systematized branch of medicine provided such an obvious means of attack that the real merits and objectives of the subject were done scant justice. Still I hope and believe that this stage of resistance and resentment, that which we had long considered our own, belongs in origin largely to another, is substantially over, and we can pass on to the consideration of what this new conception means in terms of action and of relief for our patients.

Dr. James, in his distinguished address has already answered this question in a broad fashion by giving us figures from his department at St. Mary's Hospital, but I am sure that he, as well as the rest of us, would be most interested by any contribution during the discussion that might enforce or dispute his guarded optimism. In particular I would like to ask Dr. James, and others, how long it usually takes them to achieve success where success is achieved, because the time factor determines so often the practicability of any line of treatment. I should like also to know something of the cases that relapse, either with the same or fresh psycho-somatic manifestations. How much does the state of world affairs or the social order at home influence the incidence of relapse and the susceptibility of cases new or relapsed to treatment? In other words, how vulnerable are these patients to influences outside the control of any doctor be he physician or psychiatrist ? Can psychiatrists show that they have substantially more to give these particular patients, backed as they are by their social psychiatric workers than the general physician can by word of hope and a bottle of medicine in partnership with his lady almoner and the social services at her command?
The limitations and scope of the physician and psychiatrist depend to my mind on the answers to these questions. If a case can' be made out that psychiatrists, have in their technics a practical answer, and that these technics are highly specialized but not so time consuming that they limit, too radically, the number of cases that can be undertaken, then I feel the general physician's relationship to the psychiatrist is limited by just the same considerations as it is with any other specialist. He will seek his opinion and help as he would that of a surgeon or a neurologist and the more he knows of the speciality himself the more intelligently will he use it. If, on the other hand, what there is to offer is based on explanation, reassurance and suggestion and on special mothods that are suitable for more general use, then I think general physicians should learn these methods and treat their patients themselves. The only limit would be the interest and competence of the individual doctor. In either case the physician should know more of psychiatry.

The suggestion, just made by Dr. James, that the best way of bringing this about is by a training analysis, is a most interesting one and I hope we shall hear people's views on it. I must confess complete ignorance of analysis, but I can at least foresee a very high degree of resistance to this idea by most of my colleagues, and that is to put it euphemistically. Be this as it may, I am certainly one with Dr. James in wishing for a more understanding attitude for these patients by the physician, and in wanting to see him treat them himself, for in this I see great advantage for the patient. Some patients distrust specialists and fear that certain aspects of their cases are apt to be overlooked by them. They feel, I am sure, greater ease in placing confidence in one who has examined them himself, rather than accepting, as some psychiatrists do, another man's assurance that there is no evidence of organic disorder. Also there are those who still resent the suggestion that they should attend the psychiatric department and feel a sense of shame and failure when the matter is approached. You may say that this is a sign of ignorance and lack of insight, of prejudice or due to the misunderstanding of words, and that it would soon pass once the patient reached the psychiatrist. This may be true, but surely there is psychotherapeutic value in a robust attitude and the assumption of a high morale, and I feel there would, be something very wrong with a society that allowed an individual to accept too willingly a psychiatric basis for his complaints although it may be the truth. I see, therefore, in these prejudices something of value, and an additional reason why the physician should be as competent as he can to deal with such cases himself. 
Finally, I would like to express the hope that at the same time as an increase in our knowledge will enable the physician and psychiatrist to be as one in treating these cases, that much misused and frequently ridiculed term psycho-somatic medicine will fall into disuse. When the physician and the psychiatrist can use the word medicine in the same sense, there will no longer be the emotional tension in a discussion between them, that has been so destructive in the past. Medicine is so great and all embracing a subject that we simply cannot afford to add to our difficulties in its practice by bickerings among ourselves, how- ever amusing they may be. Moreover, if Dr. James is right; and we are the last hope of a world peopled by immensely powerful but maladjusted and destructive children, to do so would be to allow a sense of humour to go a little too far. We must be free to exercise that quality of judgment that you, Sir, extolled so ably in your Presidential Address to this section when you first took office and, in our pursuit of truth we must forget, at any rate with each other, that devastating injunction of Voltaire's, 'to walk ever on the path of truth with a sneer.'

\section{LAY CLINICIANS}

No. 13

Often when reading a book or play one comes across an excellent description of some disease. Such accounts are always of interest to the doctor and they often show surprisingly accurate powers of observation and clinical acumen. We hope to print some of these 'case records' from time to time and for those who would like to tris their hand at naming the author, this information will be given at the end of the extract.

' The harmful cerussa, that most noxious thing Which foams like the milk in the earliest spring With rough force it falls and the pail beneath fills This fluid astringes and causes grave ills.

The mouth it inflames and makes cold from within

The gums dry and wrinkled, are parched like the skin

The rough tongue feels harsher, the neck muscles grip

He soon cannot swallow, foam runs from his lip

A feeble cough tries, it in vain to expel
He belches so much, and his belly does swell His sluggish eyes sway then he totters to bed Complains that so dizzy and heavy his head Phantastic forms flit now in front of his eyes While deep from his breast there soon issue sad cries

Meanwhile there comes a stuporous chill

His feeble limbs droop and all motion is still

His strength is now spent and unless one soon aids

The sick man descends to the Stygian shades.'

This description of lead poisoning was written by the Greek poet Nicander in the second century B.C. The text printed here is translated from a latin version which appeared in the 16 th century. Practically all the recognized symptoms and signs of plumbism are recorded in these verses.

\section{JONATHAN FALLOWFIELD. LTD. \\ 87 NEWMAN STREET, W.I \\ TEL.: MUSEUM 7401-2 \\ Specialists in $X$-ray and Photographic Materials ESTABLISHED IN 1856}

